\title{
IMPLEMENTASI DYNAMIC SYSTEM DEVELOPMENT METHOD (DSDM) PADA SISTEM INFORMASI MANAJEMEN BENGKEL MOBIL BERBASIS WEB
}

\author{
Dewi Ayu Nur Wulandari ${ }^{1}$, Muhammad Dika Atthariq ${ }^{2}$, Wahyu Dwi Nanda ${ }^{3}$ Lestari Yusuf $^{4}$ \\ 1,2,3 Program Studi Sistem Informasi Kampus Kota Bogor, Fakultas Teknik dan Informatika Universitas Bina Sarana \\ Informatika \\ Jl. Kramat Raya No. 98, Jakarta Pusat, DKI Jakarta, Indonesia \\ ${ }^{4}$ Program Studi Sistem Informasi, Sekolah Tinggi Manajemen dan Informatika Nusa Mandiri \\ Jl. Kramat Raya No 18, Jakarta Pusat, DKI Jakarta, Indonesia
}

\author{
1'dewi.dan@bsi.ac.id \\ ${ }^{2}$ muhammadikaattariq@gmail.com \\ ${ }^{3}$ wayawdwinanda@gmail.com \\ ${ }^{4}$ lestari.lyf@ nusamandiri.ac.id
}

\begin{abstract}
Abstrak - Dalam mengembangkan dan membangun sebuah perangkat lunak kita dapat menggunakan metode Dynamic System Development Method (DSDM). DSDM merupakan metode pemngembangan perangkat lunak dimana aplikasi yang dibangun berdasarkan kebutuhan dan komunikasi antara pengguna dan pengembang. Tujuan dari penelitian ini adalah membuat aplikasi Sistem Informasi Manajemen Bengkel pada Bengkel DK Variasi dengan tujuan untuk meminimalkan kesalahan yang mungkin terjadi pada saat pengadaan stok barang yang meliputi pembelian spare part, penerimaan spare part, retur dan penerimaan retur. Proses pembuatan aplikasi ini menggunakan tahapan-tahapan yang ada pada DSDM yang dimulai dari menganalisa sistem kerja dan prosedur yang digunakan saat ini pada Bengkel DK Variasi. Kemudian dari hasil analisa tersebut, dilanjutkan dengan mendesain business sytem dengan menggunakan UML. Selanjutnya pembuatan desain database yang terdiri dari 8 entitas, yang kemudian di-generate ke aplikasi basis data untuk membuat database yang nantinya akan digunakan dalam menyimpan data serta desain input dan output. Tahap terakhir yaitu mengimplementasikan program yang telah disusun dan database yang telah dirancang keprogram berbasis web kemudian dilanjutkan dengan proses pengujian sistem terhadap fitur-fitur pada proses pembelian spare part, penerimaan spare part, retur dan penerimaan retur dengan menggunakan blackbox testing sebelum akhirnya di implementasikan. Implementasi dari aplikasi ini dapat memudahkan pengguna dalam menjalankan proses bisnis yang berjalan pada bengkel DK Variasi khususnya dalam mengelola data sparepart, mengelola data barang masuk dan data barang keluar, pencatatan data transaksi service dan pengelolaan laporan data sparepart, laporan transaksi, laporan barang masuk dan barang keluar. Dengan diimplementasikannya aplikasi ini, maka proses pencatatan yang sebelumnya masih dilakukan secara manual sudah tergantikan dengan sistem yang terkomputerisasi sehingga semua transaksi dapat terdokumentasi dengan baik.
\end{abstract}

Kata kunci : Sistem, Sistem Informasi, Dynamic System Development Metthod, DSDM, Agile

\section{Pendahuluan}

Perkembangan otomotif di Indonesia membuka peluang usaha baru, salah satunya adalah usaha bengkel. Bengkel DK Variasi merupakan usaha yang bergerak dalam bidang jasa perbaikan mobil dan juga menjual berbagai jenis spare part mobil. Perkembangan teknologi dan informasi telah merambah ke berbagai bidang salah satunya adalah dunia industri. Dalam dunia industri masih ditemukan beberapa bisnis yang masih belum menggunakan teknologi informasi dalam menjalankan bisnisnya, yaitu dalam bisnis perbengkelan [1].

Kenyataannya yang terjadi sekarang adalah penggunaan teknologi informasi dapat menunjang peningkatan pelayanan terhadap pelanggan. 
Dalam menjalankan usahanya, Bengkel DK Variasi masih terdapat beberapa masalah yang dihadapi dikarenakan proses yang dilakukan belum sepenuhnya menggunakan teknologi informasi. Pengolahan data transaksi service, dan laporan penjualan spare parts maupun laporan keuangan yang masih dilakukan secara manual atau belum terkomputerisasi sehingga dalam menjalankan transaksinya masih ditemui kesalahan-kesalahan seperti dalam pencatatan data barang, data supplier yang tidak terdokumentasi dengan baik, pencatatan transaksi pembelian dan penerimaan barang yang kurang efisien, pembayaran invoice yang sering terlewat karena tidak terdokumentasi dengan baik, serta pembuatan laporan-laporan setiap bulannya.

Pesatnya perkembangan bisnis yang beradaptasi dengan teknologi informasi telah mendorong terjadinya persaingan bisnis. Setiap pelaku bisnis berlomba-lomba untuk mendapatkan pangsa pasar dan menarik pelanggan untuk menggunakan produk atau layanan perusahaannya [2]

Untuk mengatasi permasalahan yang terjadi terkait tentang transaksi jasa service kendaraan dan untuk memonitoring ketersediaan sparepart yang sesuai untuk mendukung aktivitas yang ada di bengkel, maka dibuatlah sistem booking service online \& monitoring sparepart dengan menggunakan bahasa pemograman PHP dan MySQL[3]

Aplikasi sistem manajemen bengkel berbasis web dibuat dengan tujuan untuk meminimalkan kesalahan yang mungkin terjadi dalam menjalankan proses bisnis pada bengkel DK Varias dan meningkatkan layanan kepada pelanggan.

Dalam pembuatan aplikasi system informasi manajemen bengkel akan digunakan tahapan-tahapan yang ada pada metode Dynamic System Development (DSDM). Metode ini mendefinisikan RAD sebagai frame work untuk menyelesaikan proyek pengembangan sistem informasi RAD, memberikan informasi dan solusi bisnis dalam batas waktu terbatas dan anggaran terbatas [4]

DSDM dipilih karena metode ini cocok dengan kondisi yang terjadi pada bengkel DK Variasi.

\section{METODOLOGI PENELITIAN}

Dalam penelitian ini, pembuatan aplikasi system informasi manajemen bengker berbasis web akan mengimplementasikan tahapan-tahapan yang ada pada metode Dynamic System Development Method (DSDM).

DSDM merupakan penyempurnaan dari metode James Martin Rapid Aplication Development Method (JMRAD). DSDM mencoba memasukkan unsur disiplin ke dalam JMRAD. DSDM dikembangkan oleh konsorsium DSDM di Eropa yang dibentuk tahun 1994 [4]

Dynamic Systems Development Method (DSDM) merupakan sebuah metode yang dapat digunakan dalam membangun atau megembangkan perangkat lunak secara berulang dan bertahap dengan melibatkan kerjasama antara pengguna dan pengembang [5]
Dynamic Systems Development Method menyediakan framework untuk membangun dan memelihara sistem dalam waktu yang terbatas dengan menggunakan prototipe incremental dalam lingkungan terbatas [6]

DSDM berasal dari komunitas pengembangan perangkat lunak, tetapi integrasi pengembangan perangkat lunak, rekayasa proses, dan proyek pengembangan bisnis mengubah kerangka kerja DSDM menjadi kerangka umum untuk memecahkan masalah yang kompleks[7]

DSDM merupakan salah satu metode yang terdapat agile software development yang digunakan untuk pengembangan perangkat lunak. DSDM adalah kerangka kerja yang awalnya didasarkan pada pengembangan aplikasi cepat (RAD), yang menggunakan metode pengembangan berulang dan bertahap dengan memprioritaskan perubahan pengguna dan partisipasi pengguna yang berkelanjutan, tanggap terhadap perubahan, untuk pembuatan Sistem perangkat lunak untuk kebutuhan bisnis [5]

DSDM Lifecycle terdiri dari 3 tahapan utama dan 5 sub tahapan seperti yang terlihat pada gambar 1.[8]

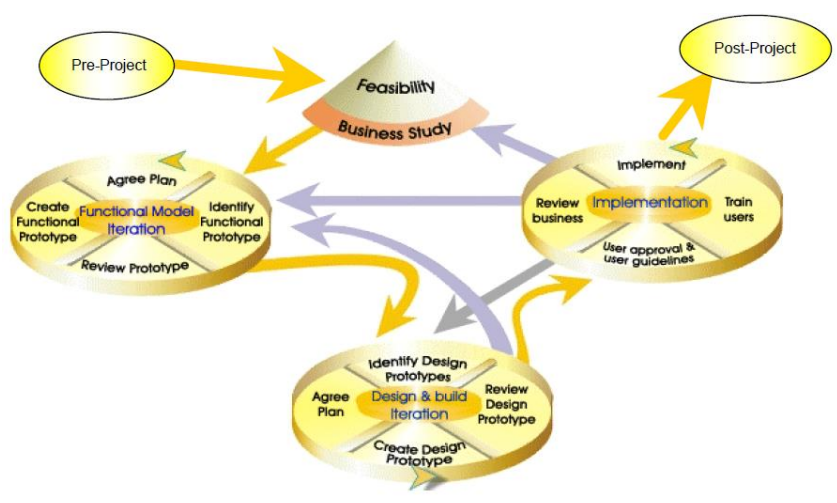

Gambar 1. DSDM Lifecycle [8]

Tahapan DSDM Lifecycle [8]:

\section{Fase Sebelum Proyek (Pre-Project)}

Untuk memastikan keberhasilan proyek, maka proyek harus disiapkan dengan benar sejak awal. Seperti mendefinisikan masalah bisnis yang akan di selesaikan, rencana awal studi kelayakan dan bisnis, anggaran dan sumber daya yang akan digunakan.

Studi kelayakan dan bisnis dilakukan secara berurutan. Dalam rencana awal studi ditetapkan aturan dasar dalam pengembangan. Aturan ini akan dilakukan berulang dan bertahap, sehingga harus diselesaikan sebelum pekerjaan lebih lanjut dilakukan pada proyek tertentu [9]

\section{Siklus Hidup Proyek (Lifecycle Project)}

Siklus hidup proyek terdiri dari lima (5) sub tahapan, yaitu :

\section{a. Studi Kelayakan (Feasibility)}


Tujuan studi kelayakan adalah untuk menilai atau memilih solusi yang paling tepat dan menetapkan apakah solusi pengembangan yang diusulkan sesuai dengan persyaratan bisnis organisasi. Dalam fase ini dilakukan penilaian apakah pendekatan DSDM adalah solusi yang tepat atau tidak untuk proyek dibandingkan dengan dengan studi kelayakan tradisional (waterfall). Hal ini dikarenakan dalam banyak studi kelayakan pendekatan waterfall secara implisit diterima sebagai pendekatan default yang digunakan untuk pengembangan [9].

b. Studi Bisnis (Bussines Study)

Studi bisnis dilakukan untuk mengetahui lingkup proses bisnis yang akan didukung dalam pengembangan aplikasi termasuk kebutuhan sistem informasi yang akan dibuat dalam tiap proses bisnisnya. Hasil fase ini adalah definisi domain bisnis yang tidak hanya akan mengidentifikasi proses bisnis dan informasi terkait, tetapi juga mengidentifikasi kategori pengguna yang akan terkait dengan sistem yang akan dirancang[9].

c. Perulangan Model Fungsional (Fuctional Model Iteration)

Tahapan ini dilakukan untuk menggambarkan model fungsional dan model statis yang dibutuhkan. Fokus dari iterasi model fungsional adalah untuk meningkatkan aspek bisnis sistem, yaitu, berdasarkan fungsi dan persyaratan informasi yang ditentukan dalam proses bisnis. Karena itu, analisis standar model dan perangkat lunak diproduksi pada waktu yang bersamaan. Iterasi model fungsional atau desain dan konstruksi mencakup empat siklus aktivitas : 1) Menentukan apa yang akan dilakukan dalam setiap siklus; 2) Setuju dengan apa yang akan dilakukan; 3) Melakukan apa yang sudah ditentukan dan disetujui; 4) Memeriksa apakah sudah melakukan dengan benar (periksa dokumentasi, prototipe demo, Atau membuktikan bahwa bagian dari perangkat lunak telah berhasil diuji) [9] .

d. Perulangan Perancangan dan Pembuatan (Design and Build Iteration)

Tahapan ini merupakan tahapan untuk menyempurnakan prototipe fungsional agar memenuhi persyaratan non fungsional agar aplikasi yang dibuat memenuhi kebutuhan pengguna. Dalam fase ini yang dilakukan adalah merancang sistem dengan standar yang cukup tinggi agar dapat digunakan sesuai dengan kebutuhan pengguna. Output dari fase ini adalah sistem yang telah diuji[9].

e. Penerapan (Implementation)

Pada tahapan ini, aplikasi yang sudah dibuat oleh pengembang kemudian digunakan oleh pengguna, dengan melakukan pelatihan kepada pengguna tentang sistem baru dan juga menentukan kebutuhan yang akan datang. Output pada tahap ini berisi semua dokumentasi yang diperlukan, antara lain: dokumentasi pengguna dan jumlah pengguna terlatih, termasuk didalamnya bukan hanya pengguna akhir, tetapi juga pengguna yang dapat memberikan solusi perbaikan untuk kebutuhan yang akan datang[9]

\section{3. $\quad$ Fase Setelah Proyek (Post Project)}

Fase ini adalah tahapan untuk menilai sistem yang telah digunakan apakah sudah sesuai dengan tujuan yang sudah ditetapkan pada tahap awal. Fase ini dapat dilakukan pada waktu yang disepakati selama proyek untuk mengevaluasi keberhasilan solusi dalam mencapai manfaat yang diinginkan [9].

\section{HASIL DAN PEMBAHASAN}

Berikut ini akan dijelaskan implementasi dari setiap tahapan-tahapan yang ada pada Dynamic System Development Method (DSDM) yang akan digunakan pada pembuatan Sistem Informasi Manajemen Bengkel Berbasis Web.

\section{Fase Sebelum Proyek (Pre-Project)}

Fase ini dilakukan untuk menentukan kerberhasilan proyek yang akan dibuat, sehingga proyek harus disiapkan dengan baik dari awal. Yang dilakukan pada tahap ini antara lain :

a. Membuat rencana studi kelayakan proyek

b. Mengidentifikasi masalah-masalah yang dihadapi pada bengkel DK Variasi terkait proses bisnis yang berjalan

c. Menginventarisir sumber daya yang akan digunakan

d. Merencanakan anggaran proyek yang akan dibutuhkan

\section{Siklus Hidup Proyek (Lifecycle Project)}

Siklus hidup proyek terdiri dari lima (5) sub tahapan, yaitu :

\section{a. Studi Kelayakan (Feasibility)}

Tahapan ini dilakukan dengan mengadakan pertemuan antara pengguna dan pengembang untuk membahas tentang rencana proyek yang akan dibuat terkait aplikasi tentang sistem informasi manajemen bengkel berbasis web yang akan dibuat. Hasil dari studi kelayakan adalah menentukan kebutuhan lebih lanjut terkait sistem yang akan dibuat, serta masa depan dari kelanjutan aplikasi yang direncanakan di masa depan. Termasuk didalamnya adalah ditetapkannya tujuan dari pembuatan aplikasi ini adalah untuk membuat sistem informasi manajemen bengkel berbasis web yang cepat, tepat dan efisien yang dapat membantu dalam proses transaksi dan pengambilan keputusan oleh pimpinan perusahaan

\section{b. Studi Bisnis (Bussines Study)}

Untuk mengetahui lingkup proses bisnis dan kebutuhan sistem informasi apa yang dibutuhkan dalam tiap prosesnya. Ada beberapa hal yang dilakukan pada tahapan ini, yaitu : 
1) Menggambarkan Business Proces Dengan Menggunakan Usecase Diagram.

Dalam sistem yang akan dibuat ini terdapat 3 macam level pengguna yang akan berinteraksi dengan sistem yaitu: Superadmin/pemilik bengkel, Supervisor, dan Mekanik. Setiap level pengguna memiliki interaksi yang sesuai dengan kebutuhan pengguna. Berikut ini adalah usecase diagram dari masing-masing level pengguna :

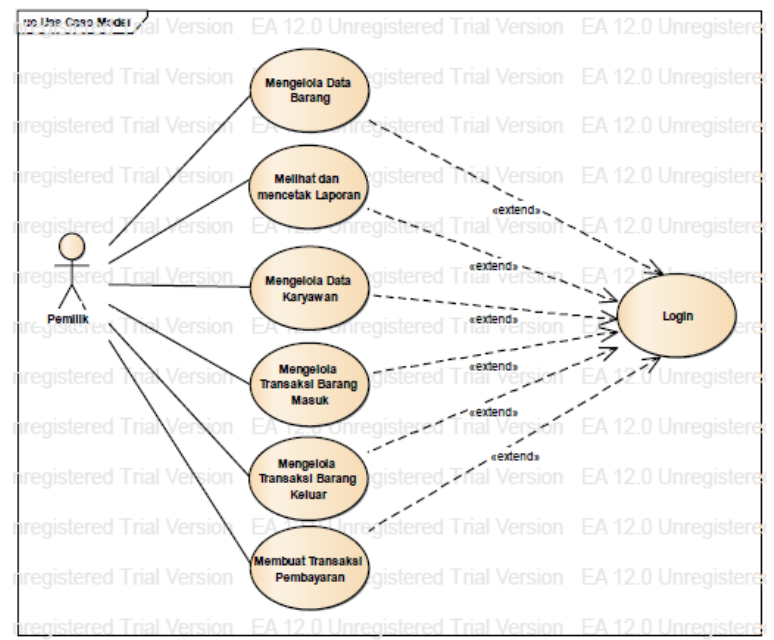

Gambar 2. Usecase Diagram Halaman Pemilik Bengkel

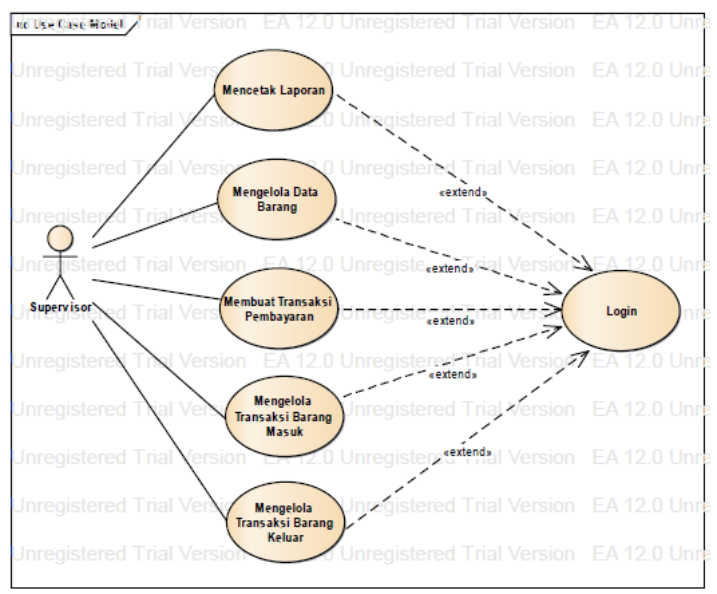

Gambar 3. Usecase Diagram Halaman Supervisor

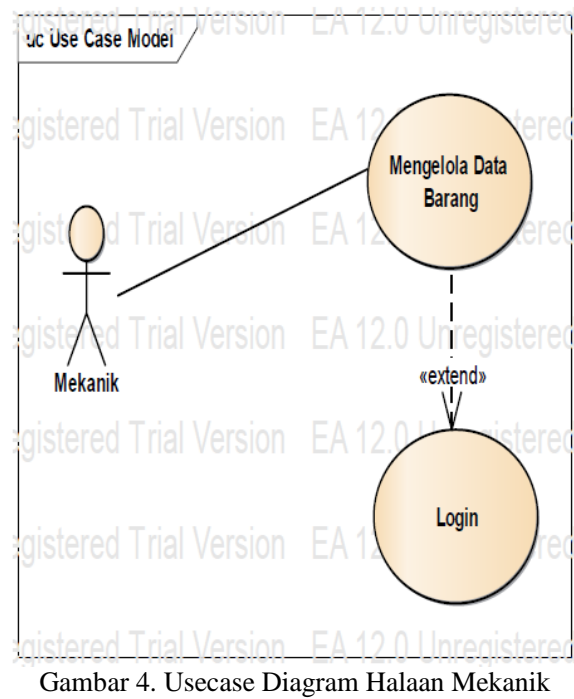

2) Menggambarkan bussiness process flow dengan menggunakan activity diagram

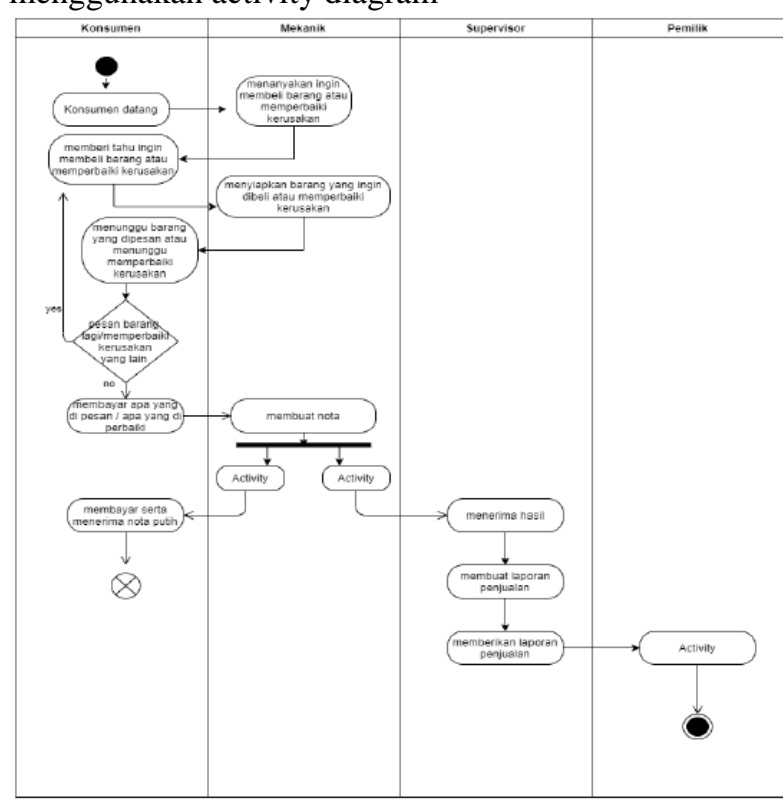

Gambar 5. Bisnis Proses

\section{c. Perulangan Model Fungsional (Fuctional Model Iteration)}

Tahapan ini dilakukan untuk menggambarkan model fungsional dan model statis yang dibutuhkan. Pada tahap ini, selain dapat menghasilkan model fungsional, non fungsional, time box plan, dan functional model review records.

Model fungsional dalam sistem ini antara lain login, menambahkan data transaksi pembayaran, menambahkan data transaksi barang masuk, menambahkan transaksi barang keluar, mengupdate data barang, melihat laporan.

Sedangkan untuk model non fungsional antara lain : pencarian data user, fungsi pencarian, pengisian halaman dashboard, mengelola data karyawan. 
TABEL I. FUNCTIONAL MODEL REVIEW RECORD

\begin{tabular}{|c|c|}
\hline Nama Fungsi & Feedback \\
\hline $\log$ In & $\begin{array}{c}\text { Jika Login Sukses, Maka Akan Tampil } \\
\text { Halaman Sesuai Dengan Level User }\end{array}$ \\
\hline Menambah Data Barang & $\begin{array}{c}\text { Jika Berhasil, Maka Data Barang Baru } \\
\text { Akan Tersimpan Dalam Database }\end{array}$ \\
\hline Menghapus Data Barang & $\begin{array}{c}\text { Jika Berhasil, Maka Data Barang Akan } \\
\text { Terhapus Dari Dalam Database }\end{array}$ \\
\hline Mengedit Data Barang & $\begin{array}{c}\text { Jika Berhasil, Maka Data Barang Baru } \\
\text { Terupdate Dan Tersimpan Dalam } \\
\text { Database }\end{array}$ \\
\hline $\begin{array}{c}\text { Menambah Data Barang } \\
\text { Masuk }\end{array}$ & $\begin{array}{c}\text { Jika Berhasil, Maka Jumlah Barang Akan } \\
\text { Bertambah Akan Tersimpan Dalam } \\
\text { Database }\end{array}$ \\
\hline $\begin{array}{l}\text { Menambah Data Barang } \\
\text { Keluar }\end{array}$ & $\begin{array}{c}\text { Jika Berhasil, Maka Jumlah Barang Akan } \\
\text { Berkurang Dan Akan Tersimpan Dalam } \\
\text { Database }\end{array}$ \\
\hline $\begin{array}{c}\text { Menambahkan } \\
\text { Transaksi Pembayaran }\end{array}$ & $\begin{array}{c}\text { Jika Berhasil, Data Pembayaran Akan } \\
\text { Tersimpan Dalam Database }\end{array}$ \\
\hline Menambah Data Karyawan & $\begin{array}{c}\text { Jika Berhasil, Maka Data Karyawan Baru } \\
\text { Akan Tersimpan Dalam Database } \\
\end{array}$ \\
\hline Menghapus Data Karyawan & $\begin{array}{c}\text { Jika Berhasil, Maka Data Karyawan Akan } \\
\text { Terhapus Dari Dalam Database }\end{array}$ \\
\hline Mengedit Data Karyawan & $\begin{array}{c}\text { Jika Berhasil, Maka Data Karyawan Baru } \\
\text { Terupdate Dan Tersimpan Dalam } \\
\text { Database }\end{array}$ \\
\hline Cetak Laporan & $\begin{array}{l}\text { Jika Berhasil Akan Menampilkan Laporan } \\
\text { Sesuai Dengan Kriteria Yang Dipilih }\end{array}$ \\
\hline
\end{tabular}

TABEL II. TIME BOX PLAN

\begin{tabular}{lll}
\hline Modul & Status & Deadline \\
\hline Log In & Selesai & Desember 2020 \\
\hline Menambah Data Barang & Selesai & Desember 2020 \\
\hline Menghapus Data Barang & Selesai & Desember 2020 \\
\hline Mengedit Data Barang & Selesai & Desember 2020 \\
\hline Menambah Data Barang Masuk & Selesai & Desember 2020 \\
\hline Menambah Data Barang Keluar & Selesai & Desember 2020 \\
\hline $\begin{array}{l}\text { Menambahkan } \\
\text { Transaksi Pembayaran }\end{array}$ & Selesai & Desember 2020 \\
\hline Menambah Data Karyawan & Selesai & Desember 2020 \\
\hline Menghapus Data Karyawan & Selesai & Desember 2020 \\
\hline Mengedit Data Karyawan & Selesai & Desember 2020 \\
\hline Cetak Laporan & Selesai & Desember 2020 \\
\hline
\end{tabular}

\section{d. Perulangan Perancangan dan Pembuatan (Design and Build Iteration)}

Tahapan ini merupakan tahapan untuk menyempurnakan prototipe fungsional agar memenuhi persyaratan non fungsional agar aplikasi yang dibuat memenuhi kebutuhan pengguna. Dalam pembuatan aplikasi ini menggunakan Cascading Style Sheet (CSS) yang terdapat dalam software Adobe Dreamweaver CS3. Struktur navigasi yang digunakan dalam pembuatan aplikasi adalah struktur navigasi campuran.

Pada tahap perancangan basis data peneliti menggunakan Entity Relational Database (ERD) sebagai alat untuk merancang relasi antar tabel dalam database untuk kemudian dikonversi ke dalam bentuk Logical Record Structure (LRS).

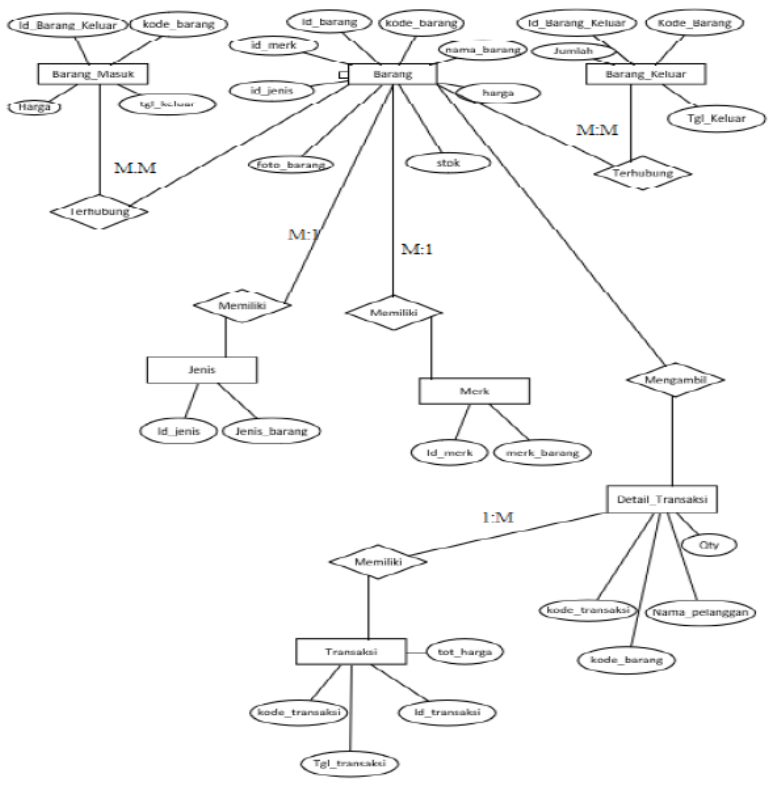

Gambar 6. Entity Relationship Diagram

Pada tahap pembuatan interface program menggunakan bahasa pemrograman PHP dan MYSQL yag dituangkan kedalam software Adobe Dreamweaver CS3 dengan menggunakan XAMPP sebagai web server. Berikut adalah beberapa contoh tampilan interface yang dibuat.

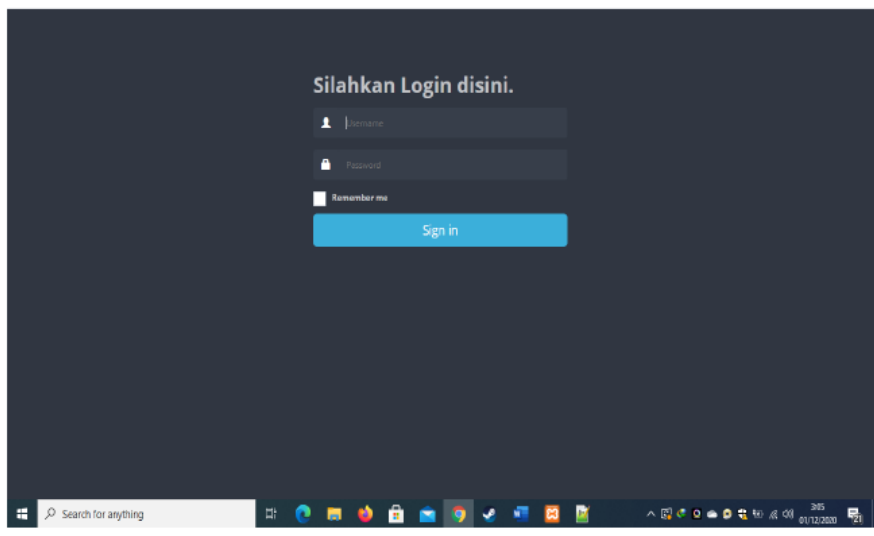

Gambar 7. Tampilan Halaman Login 


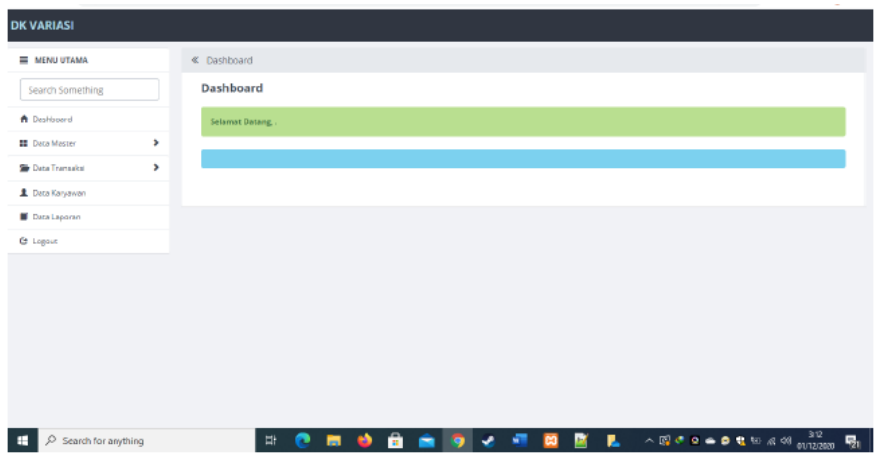

Gambar 8. Tampilan Halaman Dashboard Admin

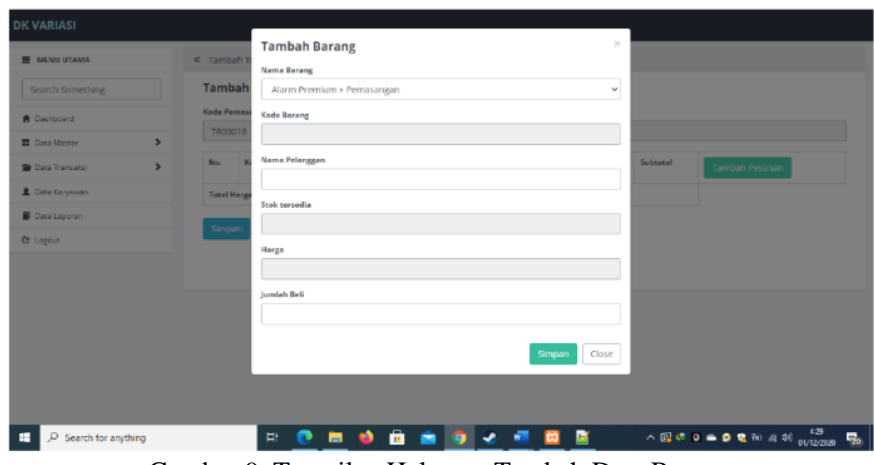

Gambar 9. Tampilan Halaman Tambah Data Barang

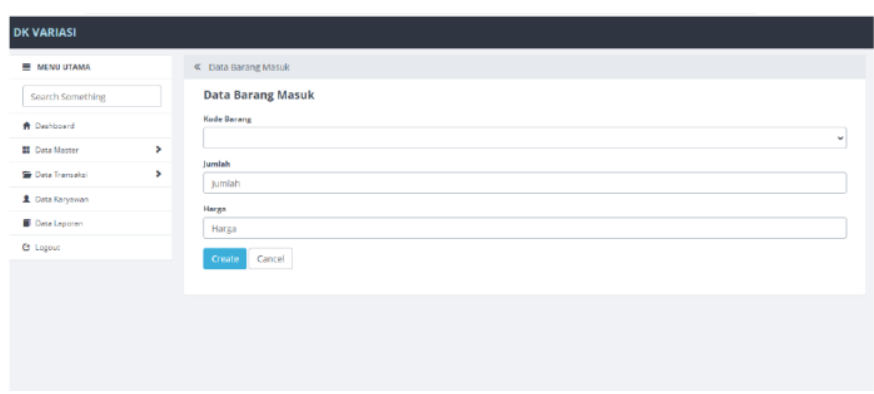

Gambar 10. Tampilan Halaman Menambah Data Barang Masuk

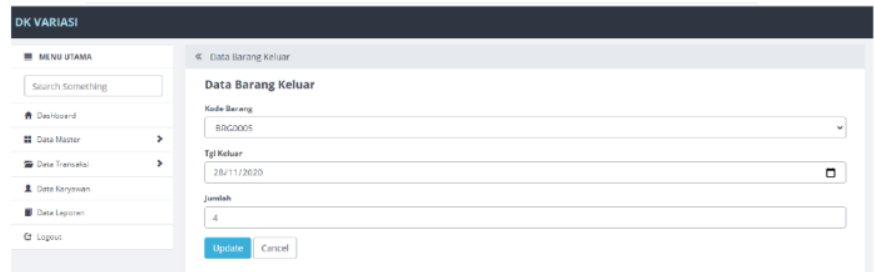

Gambar 11. Tampilan Halaman Menambah Data Barang Keluar

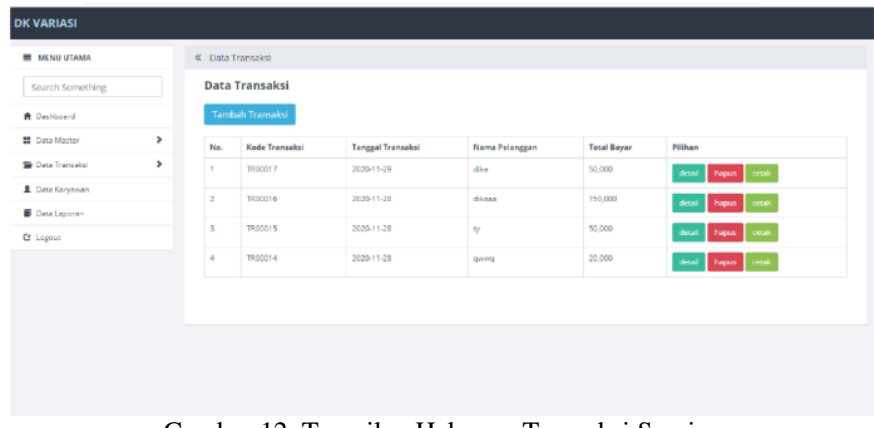

Gambar 12. Tampilan Halaman Transaksi Service

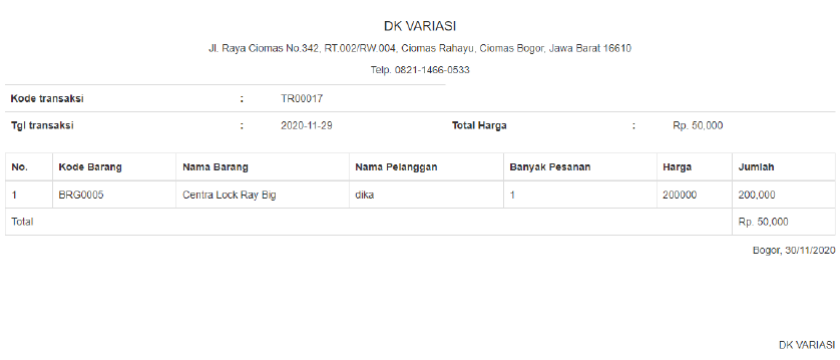

Gambar 13. Tampilan Cetak Transaksi Service

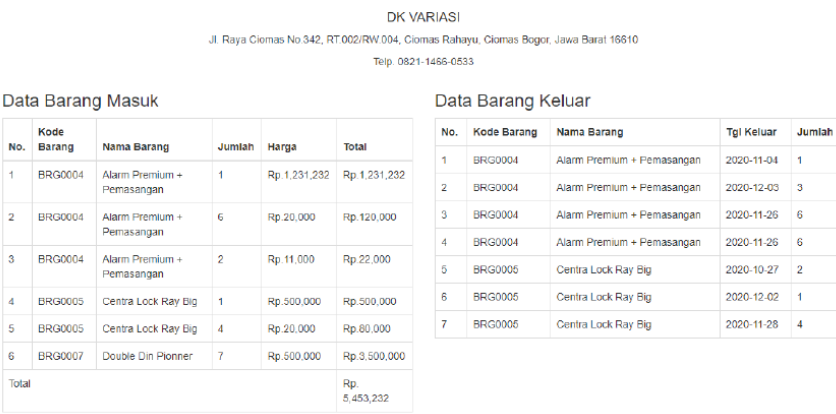

Gambar 14. Tampilan Laporan Data Barang Masuk dan Barang Keluar

Pada tahap ini juga dilakukan pengujian system dengan menggunakan teknik pengujian blackbox testing. Pengujian ini dilakukan untuk menemukan letak kesalahan (error) yang diakibatkan oleh kesalahanan penulisan kode program atau kesalahan logika pemrograman dan memastikan bahwa output yang dihasilkan sesuai dengan kebutuhan user dan prototype yang diinginkan.

Berikut ini adalah contoh hasil pengujian pada halaman login user

TABEL III. PENGUJIAN HALAMAN LOGIN USER

\begin{tabular}{llllll}
\hline No & $\begin{array}{c}\text { Skenario } \\
\text { Pengujian }\end{array}$ & Test Case & $\begin{array}{c}\text { Hasil Yang } \\
\text { Diharapkan }\end{array}$ & $\begin{array}{c}\text { Hasil } \\
\text { Pengujian }\end{array}$ & Kesimpulan \\
\hline 1. & Username & Username: & Ada & & \\
& Dan & (Kosong) & Notifikasi & & \\
& Password & Password: & Username & & Valid \\
& Tidak Diisi & (Kosong) & Dan & Sesuai & \\
& Kemudian & & Password & Harapan & \\
& Klik Tombol & & Salah & & \\
& Login & & & &
\end{tabular}




\begin{tabular}{lllcl}
\hline 2. Username & Username: & Login Gagal & & \\
Dan & Admin & Dan Muncul & \\
Password & Password: & Notifikasi & & \\
Benar Tapi & Admin & & Sesuai & Valid \\
Level Salah & Level: & & Harapan & \\
& Pemilik & & & \\
& Toko & &
\end{tabular}

\begin{tabular}{lllll}
\hline 3. Username, & Username: & Login & & \\
Password & Admin & Berhasil & \\
Dan Level & Password: & Masuk Ke & \\
Benar & Admin & Halaman & Sesuai & Valid \\
& Level: & Dahboard & Harapan & \\
& Pemilik & & & \\
& Toko & & &
\end{tabular}

\section{e. Penerapan (Implementation)}

Fase implementasi dilakukan setelah program yang dirancang selesai dibuat. Pada tahapan ini dilakukan pelatihan penggunaan program aplikasi yang dibuat kepada pengguna. Hal ini perlu dilakukan agar pengguna dapat meningkatkan kemampuan dan menggunakan program aplikasi sesuai dengan tujuan pembuatan. Selain itu pada tahapan ini juga akan dilihat hasil penggunaaan aplikasi oleh pengguna terdapat eror pada system, sehingga dapat direncanakan perbaikan untuk selanjutnya.

Berdasarkan rancangan system, maka aplikasi ini dibuat dengan menggunakan bahasa pemrograman PHP dan MYSQL yang dituangkan kedalam software Adobe Dreamweaver CS3 dengan menggunakan XAMPP sebagai web server. Bahasa pemrograman PHP dipilih dan digunakan dalam perancangan aplikasi ini karena PHP dapat terintegrasi dengan baik dengan database MySQL dan juga PHP dapat berjalan lancar diberbagai platform Operating System (OS) (multiplatform).

Agar aplikasi yang dirancang dapat berjalan dengan baik, maka dibutuhkan spesifikasi minimal perangkat keras dan perangkat lunak yang mendukung sebagai berikut :

1) Perangkat Lunak

Perangkat lunak yang dibutuhkan dalam perangcangan aplikasi ini adalah :

a) Sistem Operasi : Windows 8 atau diatas nya

b) Web Server : PhpMyAdmin

c) Bahasa Pemrograman : PHP dengan Code Ignitier

d) Browser : Google Chrome atau Mozilla Firefox

2) Perangkat Keras

Perangkat Keras yang dibutuhkan dalam perancangan aplikasi ini adalah :

a) Processor : AMD A9-9420 Radeon R5, 5 Compute Cores $2 \mathrm{C}+3 \mathrm{G} 3.00 \mathrm{GHz}$ atau setara/diatasnya

b) Memory : $4.00 \mathrm{~GB}$ atau diatasnya

c) Mouse : Optical Mouse

d) Monitor e) Keyboard

Berdasarkan hasil pengujian yang telah dilakukan, aplikasi yang di rancang sudah dapat memenuhi kebutuhan pengguna seperti : 1) Mengelola data karyawan, 2) Mengelola data sparepart, 3) Mengelola data barang masuk, 4) Mengelola data barang keluar, 5) Mencetak nota pembayaran service, 6) Mencetak laporan sesuai kebutuhan.

Dengan demikian maka semua fitur yang ada di sistem dapat diimplementasikan sehingga membantu dan memudahkan pengguna dalam menjalankan aktivitas bisnis perusahaan

\section{Fase Setelah Proyek (Post Project)}

Setelah setiap tahapan pada siklus hidup proyek DSDM dilakukan berulang-ulang hingga aplikasi yang di rancang selesai dibangun sesuai dengan kebutuhan sistem dan pengguna dan dapat diimplementasikan, perlu adanya perawatan, perbaikan dan peningkatan fungsi pada aplikasi. Hal tersebut dapat dilakukan bersamaan dengan penggunaan aplikasi oleh pengguna, sehingga dapat terlihat apakah aplikasi yang sudah dibuat dan diimplementasikan sudah sesuai dengan yang direncanakan pada tahap awal proyek atau perlu dilakukan pengembangan selanjutnya agar aplikasi dapat lebih baik lagi sesuai dengan tahapan yang ada pada DSDM, yaitu perulangan dan pertambahan.

\section{KESIMPULAN}

Metode Dynamic System Development Method (DSDM) yang digunakan sangat membantu dalam pembuatan aplikasi Sistem Informasi Manajemen Bengkel Berbasis Web. Hal ini dimungkinkan karena dalam tahapan DSDM ada tahap perulangan dan pertambahan yang mengakibatkan adanya komunikasi yang intensif antara pengguna dan pengembang. Tahapan-tahapan yang ada pada DSDM membantu aplikasi yang dibuat sesuai dengan kebutuhan pengguna. Implementasi dari aplikasi ini dapat memudahkan pengguna dalam menjalankan proses bisnis yang berjalan pada bengkel DK Variasi khususnya dalam mengelola data sparepart, mengelola data barang masuk dan data barang keluar, pencatatan data transaksi service dan pengelolaan laporan data sparepart, laporan transaksi, laporan barang masuk dan barang keluar. Dengan diimplementasikannya aplikasi ini, maka proses pencatatan yang sebelumnya masih dilakukan secara manual sudah tergantikan dengan sistem yang terkomputerisasi sehingga semua transaksi dapat terdokumentasi dengan baik. Untuk selanjutnya pengembangan sistem informasi dapat dilakukan dengan menggunakan metode agile yang berbeda seperti scrum programming atau extreme programming dan dapat berbasis android (mobile programming). 


\section{UCAPAN TERIMA KASIH}

Terima kasih kami ucapkan kepada Bengkel DK Variasi yang telah memberikan kesempatan kepada kami untuk melakukan riset, dan juga kepada semua pihak yang tidak dapat kami sebutkan satu persatu sehingga artikel ilmiah ini dapat selesai dan dipublikasikan.

\section{REFERENSI}

[1] M. Audrilia and A. Budiman, "Perancangan Sistem Informasi Manajemen Bengkel Berbasis Web (Studi Kasus : Bengkel Anugrah)," J. Madani Ilmu Pengetahuan, Teknol. dan Hum., vol. 3, no. 1, pp. 1-12, 2020, doi: 10.33753/madani.v3i1.78.

[2] Y. Y. Welim, W. T.W., and R. Firmansyah, "Pengembangan Sistem Informasi Service Kendaraan Pada Bengkel Kfmp," Simetris J. Tek. Mesin, Elektro dan Ilmu Komput., vol. 6, no. 1, p. 17, 2015, doi: 10.24176/simet.v6i1.232.

[3] I. S. D. Nugroho, R. Wirawan, and R. M. bunga Wadu, "Perancangan Sistem Informasi Service Booking Online dan Monitoring Sparepart Barang Berbasis Web pada Bengkel AHASS PT . Wahana Makmur Sejati Irwan Setyo Dwi Nugroho , Rio Wirawan ," in Seminar Nasional Informatika, Sistem Informasi dan Keamanan Siber (SEINASI-KESI), 2019, pp. 24-25.

[4] T. Tumini and S. Sugiyanti, "Penerapan Dynamic System Development Method Pada Sistem Monitoring Status Gizi Balita," Informatics Digit. Expert, vol. 2, no. 1, pp. 7-13, 2020, doi: 10.36423/ide.v2i1.426.

[5] L. Rusdiana, "Dynamic Systems Development Method dalam membangun Aplikasi Data Kependudukan Pada Kelurahan Rantau Pulut," J. Transform., vol. 16, no. 1, p. 84, 2018, doi: 10.26623/transformatika.v16i1.859.

[6] W. Nyunando and D. Nasien, "Implementasi Agile Dynamic System Development Method Berbasis Web Pada Sistem Penggajian," J. Mhs. Apl. Teknol. Komput. dan Inf., vol. 2, no. 1, pp. 33-38, 2020.

[7] B. J. . J. Voigt, Dynamic System Development Method, no. January. Zurich, 2004.

[8] D. Concortium and T. O. G. A. Forum, DSDM (Dynamic Systems Development Method) and TOGAF (The Open Group Architecture Framework). .

[9] D. Consortium, DSDM Bussines Focus Development, Second Edi., vol. 53, no. 9. Addison-Westley, 2015. 